\title{
BASES CONCEPTUALES DE LA RENDICIÓN DE CUENTAS Y EL ROL DE LAS ENTIDADES DE FISCALIZACIÓN SUPERIOR
}

\author{
Jimmy Bolaños González \\ Contraloría General de la República, Costa Rica \\ jimmy.bolanos@cgr.go.cr
}

\section{RESUMEN}

El sistema político democrático, la propia Administración Pública y los ciudadanos han venido madurando el desarrollo de algunos nuevos instrumentos que permitan a los gestores públicos gobernar bien pero también que permitan a los ciudadanos controlar apropiadamente esa gestión, y parte sustancial de esas herramientas es lo que se conoce como rendición de cuentas. Este ensayo pretende sentar las bases conceptuales del abordaje de esa herramienta desde el rol que está llamada a cumplir la Contraloría General de la República de Costa Rica, para generar un lenguaje común capaz de servir de base para el tratamiento de los aspectos prácticos involucrados en esta temática, que en un segundo ensayo serán abordados desde el ámbito jurídico y administrativo-operativo más concreto de cómo ha venido operando en Costa Rica.

PALABRAS CLAVE: BUEN GOBIERNO, RENDICIÓN DE CUENTAS, ENTIDADES DE FISCALIZACIÓN SUPERIOR, GOBERNABILIDAD, TEORÍA DE SISTEMAS, EMOCRACIA

\section{ABSTRACT}

The democratic political system of our countries, public administration and citizens have been developing some new instruments that help public managers govern well and at the same time allow citizens to appropriately control government actions. Accountability is an important one of these instruments. This work tries to lay the conceptual foundations of accountability in relation to the role the Comptroller General of the Republic is to fulfill so as to generate a common language capable of functioning as a basis for addressing the practical aspects involved in this topic. Such aspects will be dealt with in a second article from a more concrete legal, administrative and operative perspective of how they have been working in Costa Rica.

KEYWORKS: GOOD GOVERNANCE, ACCOUNTABILITY, SUPERIOR ACCOUNTABILITY ORGANIZATIONS, GOVERNABILITY, THEORY OF SYSTEMS, DEMOCRACY

\section{INTRODUCCIÓN}

En el presente ensayo nos proponemos presentar las nociones básicas que modernamente se manejan en el tema de la Rendición de Cuentas (en adelante RC), con los siguientes objetivos:

1. Exponer los conceptos fundamentales que están a la base de la rendición de cuentas, como característica esencial del buen gobierno.

2. Plantear la rendición de cuentas como un sistema integral con múltiples requerimientos que aseguren su calidad, pertinencia y credibilidad.

3. Resaltar la importancia de la Entidades de Fiscalización Superior en la rendición de cuentas y el buen gobierno dentro de un sistema democrático. 
Por su enfoque introductorio, general y supranacional, intencionalmente se han obviado referencias normativas y jurisprudenciales, las cuales serán objeto de estudio en un segundo ensayo que tratará del tema de la RC en el ordenamiento jurídico costarricense.

El interés del autor en sistematizar el complejo teórico doctrinal que sustenta la $\mathrm{RC}$, reside en permitir un abordaje amplio de esta temática, que siente las bases para una mejor comprensión de la misma por parte de los funcionarios públicos en general y de los ciudadanos en particular, además de que propicie el interés en ulteriores profundizaciones en las que se continúe debatiendo acerca de las distintas aristas de este vital tema, en el que convergen varias disciplinas como la economía, las ciencias políticas, el derecho, la contabilidad pública, la administración pública, la ingeniería industrial, la sociología, entre otros.

\section{¿Qué es la Rendición de Cuentas?}

La Rendición de Cuentas (RC) es la obligación de toda persona a la que le es conferida una responsabilidad, de dar cuenta del encargo recibido, haciendo un descargo que puede ser satisfactorio o insatisfactorio, debiendo provocar en el primer caso reconocimiento o efectos favorables, y en el segundo caso desaprobación o consecuencias negativas.

Sobre la noción de RC ofrecemos algunas definiciones:

TABLA 1

\section{DIVERSAS DEFINICIONES DE RENDICIÓN DE CUENTAS}

\begin{tabular}{|c|c|}
\hline AUTOR & DEFINICIÓN \\
\hline $\begin{array}{l}\text { Oficina del Auditor } \\
\text { General de Canadá } \\
\text { (1975) }\end{array}$ & $\begin{array}{l}\text { La obligación de responder ante la responsabilidad que ha sido conferida (...) supone la } \\
\text { existencia de al menos dos partes: una que confiere la responsabilidad y otra que acepta } \\
\text { esa responsabilidad" (...).* }\end{array}$ \\
\hline $\begin{array}{l}\text { Scout Mainwaring } \\
\qquad(2003)\end{array}$ & $\begin{array}{l}\text { (...) la rendición de cuentas política (...) refiere a la obligación de responder y a la responsabili- } \\
\text { dad de los funcionarios públicos (...) La rendición de cuentas política es pues una relación for- } \\
\text { malizada de supervisión o sanción de los funcionarios públicos por parte de otros actores". * }\end{array}$ \\
\hline $\begin{array}{l}\text { Barbara Romzek } \\
\text { y Melvin Dubnick } \\
\text { (1998) }\end{array}$ & $\begin{array}{l}\text { "una relación en la cual un individuo o una agencia está obligado a responder por aquel } \\
\text { desempeño que involucra alguna delegación de autoridad para actuar".* }\end{array}$ \\
\hline $\begin{array}{l}\text { Jay Shafritz } \\
\text { (1988) }\end{array}$ & $\begin{array}{l}\text { "El ámbito en el cual una persona debe responder ante una autoridad superior -sea esta } \\
\text { legal u organizacional- por las acciones realizadas en la sociedad dentro de los límites } \\
\text { de su posición organizacional". * }\end{array}$ \\
\hline $\begin{array}{c}\text { Andreas Schedler } \\
\text { (1999) }\end{array}$ & $\begin{array}{l}\text { "Más que denotar una técnica específica de domesticar el poder, [la noción de rendición } \\
\text { de cuentas política] abarca tres diferentes formas de prevenir y corregir el abuso del } \\
\text { poder político. También implica la sujeción del poder a la amenaza de sanciones, el } \\
\text { obligarlo a ser ejercido de forma transparente, y el forzarlo a justificar sus actos". * }\end{array}$ \\
\hline $\begin{array}{l}\text { Rodolfo Saborío } \\
\text { (2003) }\end{array}$ & $\begin{array}{l}\text { "La rendición de cuentas, a partir del enfoque sistémico que dispone la Constitución Política [de } \\
\text { Costa Rica], consiste en la obligación a cargo de todo titular de competencias públicas de actuar } \\
\text { apegado al ordenamiento jurídico, de ejercer en forma ética, económica, eficaz y eficiente sus } \\
\text { competencias y de generar y proporcionar la información necesaria y suficiente para que su ac- } \\
\text { tividad sea evaluada. Este concepto implica paralelamente la obligación, a cargo de terceros, de } \\
\text { evaluar los resultados de dicha gestión, tomando en cuenta tanto el respeto de las disposiciones } \\
\text { normativas aplicables como el cumplimiento de los objetivos y metas previamente establecidos } \\
\text { (preferiblemente en el instrumento en que se le asignan los recursos presupuestarios para cumplir } \\
\text { con sus funciones) con la consecuente responsabilidad en caso de incumplimiento". }\end{array}$ \\
\hline * Traducción lik & nglés. Se ha traducido el término "accountability" como "ren \\
\hline
\end{tabular}


La RC siempre ha existido y siempre existirá porque en toda organización social hay personas que asignan la responsabilidad (cuerpo gobernante o mandante) y personas que aceptan la responsabilidad (mandatarios).

La RC existe también en toda organización política, ya que los mismos poseedores del poder o soberanos (cuerpo gobernante o mandante) aún en los Estados absolutistas y en los Estados autoritarios requieren de mecanismos para controlar la conducta de sus subordinados (cuerpo obediente), pero en estos casos, el monarca o soberano no suele responder ante nadie por su conducta.

En la democracia, el soberano es el pueblo (cuerpo mandante) y éste elige a sus gobernantes en elecciones periódicas, mecanismo con el cual confieren un mandato o responsabilidad, debiendo ser cumplido conforme a unas reglas (marco constitucional e infraconstitucional) que juran cumplir al tomar posesión del cargo público, reglas que marcan las potestades, las obligaciones y las responsabilidades con las cuales ha de ser ejercido, régimen que se extiende en lo conducente a todos los demás funcionarios y servidores públicos.

La RC es consustancial a la democracia, es decir, constituye un elemento no accesorio sino esencial a esta forma de gobierno, de modo que los gobernantes y todo funcionario debe responder por sus actos $u$ omisiones graves ante el pueblo o los órganos públicos de control.

La RC vista desde el punto de vista ciudadano se concibe como un derecho que nace con la Declaración de los Derechos del Hombre y del Ciudadano, adoptada en Francia del 26 de agosto de 1789, la cual establecía en el artículo 14: "Todos los ciudadanos tienen el derecho de verificar por sí mismos, por sus representantes la necesidad de la contribución pública, de aceptarla libremente, de vigilar su empleo, y de determinar la cuota, la base, la recaudación y la duración".
Asimismo, el artículo 15 disponía también que: "la sociedad tiene derecho de pedir cuentas a todo agente público sobre su administración".

Nótese que ya desde ese entonces claramente se estableció el derecho de vigilancia ciudadana sobre el empleo de las contribuciones públicas y el derecho de pedir cuentas a los gestores públicos sobre su administración, derecho que generan el correlativo deber del gobernante y funcionario de rendir cuentas de su gestión y conducta.

Se entiende la RC como aquel deber jurídicamente regulado de gobernantes y funcionarios públicos consistente en la obligación de informar y/o estar dispuestos a explicar los distintos aspectos involucrados en su gestión de los asuntos que interesan a todos, con la consiguiente posibilidad de responsabilización múltiple que de ello derive.

De ahí que como bien apunta la Contraloría General de Chile:

El Banco Mundial ha definido la Rendición de Cuentas a partir de dos componentes fundamentales, cuales son, la obligación que asiste a políticos y funcionarios quienes administran los recursos públicos -considerados en su sentido más amplio, de informar y justificar sus actos ante quienes les han delegado dicha capacidad, esto es, la ciudadanía, y la capacidad de sancionarlos cuando ellos violen o incumplan sus obligaciones (enforcement) (2005, p. 4).

Este principio de responsabilidad de los agentes públicos, solo o enraizado con otros principios como el de publicidad, transparencia, entre otros; se refleja implícita o explícitamente en la mayoría de las constituciones de tradición latina, claro está, con diferentes niveles de desarrollo, intensidad o especialidad. 
Por su parte, la literatura inglesa habla de "accountability" para referirse a la RC, término muy utilizado en los EEUU y Canadá para referirse a "la obligación legal y ética de todos los que ejercen la autoridad de rendir cuentas sobre la manera en que han utilizado los recursos y en general como han cumplido las responsabilidades que les han sido confiadas por el pueblo" (CGR, 1998, p.18).

La difícil traducción del término "accountability" en lengua española originalmente se había hecho bajo la expresión RESPONDABILIDAD, e incluso en la XIX Conferencia de Contabilidad dirigida a quinientos mil contadores públicos del continente americano se formuló la siguiente recomendación oficial:

La Asociación Interamericana de Contabilidad reconoce formalmente el concepto Responsabilidad y se compromete a fomentar su aceptación oficial en el idioma español, como el deber de toda persona que maneja bienes o dinero, o que ha recibido la encomienda de realizar cualquier tarea por parte de otros, de responder sobre la forma en que cumple sus obligaciones, incluida la información suficiente sobre la administración sobre los fondos y bienes. Esta obligación implica la de establecer una estructura adecuada de organización para cumplirla, la que deberá ser verificada por una entidad independiente y superior (Analdo, p. 6).

Especialistas en esta materia muy influyentes en América Latina como el argentino Oscar Oszlak, han preferido utilizar el término "responsabilización", atendiendo a diferencias entre las culturas anglosajonas y latinas.

Se señala que en la cultura anglo el punto de partida de la conceptualización de la accountabilitity se sitúa en el funcionario público, a quien se impone el deber de rendir cuentas y ante quien lo debe hacer: un organismo de control, al Congreso o a la sociedad misma.
Por el contrario, en la cultura de América Latina hay un cambio de perspectiva, en el tanto la noción RC tradicionalmente se ha asociado a la potestad o competencia de un órgano de control, ejercida en el ámbito de sus competencias, más que a un deber cotidiano del gobernante o funcionario público, por cuyo indebido u omiso ejercicio poco se suele reparar, y más poco aún se suele responsabilizar.

Esto implica un reto muy importante para el sistema de RC en la región, ya que debe reforzarse el sentido de responsabilidad del funcionario acerca del significado, alcances y exigencias concretas derivadas del cumplimiento tradicionalmente pobre y poco claro de este deber, así como las condiciones facilitadoras que lo hagan material, efectiva y jurídicamente posible.

Asimismo, ha de propiciarse una mayor conciencia cívica en la ciudadanía acerca de sus derechos y responsabilidades con respecto a lo que el funcionario ha hecho con el mandato y recursos otorgados, es decir, que todo ciudadano sepa que tiene derecho a pedir cuentas y cómo puede ejercer ese derecho.

A su vez, el papel de los órganos públicos de control como el Parlamento, las Entidades de Fiscalización Superior -en adelante EFS-, los Tribunales de Justicia, el ombusman, las auditorías internas, deben favorecer el escrutinio ciudadano, así como también es necesario que el quehacer de estos órganos no sea visto en forma aislada unos de los otros, sino complementaria, combinada y articulada en un sistema integrado de RC, que debe operar con más amplia apertura informativa y transparencia hacia la ciudadanía y los medios de comunicación social.

Finalmente, cabe señalar que autores como Catalina Smulovitz y Enrique Peruzzotti (p. 22) han utilizado el término "accountability social" para indicar el mecanismo de control de las autoridades públicas ejercido por la sociedad civil, movimientos ciudadanos y los medios de comuni- 
cación social, demandando respuestas por las actuaciones cuestionadas de funcionarios públicos, denunciándolas así como haciendo protesta social y realizando una exposición mediática de esas situaciones y de los funcionarios involucrados en los medios de comunicación social.

\section{¿Dónde se origina la RC como deber?}

La obligación de RC nace de dos fuentes: una normativa u externamente impuesta, ya sea por la Constitución, las leyes y los reglamentos; y otra como deber autoimpuesto, el cual surge como respuesta al propio convencimiento, predisposición o sentido de responsabilidad del político o funcionario público.

Sin embargo, en la práctica institucional y de los funcionarios públicos la RC rara vez es voluntaria. Por lo tanto, su concepción como obligación normativamente impuesta y desarrollada tiene la ventaja de generar garantías de estabilidad en las reglas, generando un trato igualitario y la sujeción a unos mismos parámetros. Pese a estas ventajas, no se construye la RC solo con leyes y coacción, porque son condición necesaria pero no suficiente.

Decimos que las leyes y las sanciones son necesarias pero no suficientes, porque los expertos suelen resaltar la necesidad de forjar toda una cultura de RC, la cual es necesaria para que la misma responda a una actitud y a unos valores éticos de frente a la responsabilidad conferida.

Asimismo, los especialistas recalcan que "esa actitud necesita de un ambiente propicio para florecer. La persona que confiere la responsabilidad tiene que tener la expectativa de que se le rinda cuentas; la persona a la que se le ha dado la responsabilidad debe estar preparada para rendir cuentas" (Analdo, p. 23 ).

Es decir, la RC exige educación y conciencia cívica en la ciudadanía, a la vez que a quienes se les ha confiado una responsabilidad han de estar concientes de que no todo es gestionar los asuntos, sino que han de hacerlo bien, de tal forma que puedan tener objetivos claros e información apropiada sobre los resultados obtenidos, para estar en condiciones de dar cuentas de su labor.

La RC a menudo no se produce fácilmente: no todos tienen la actitud apropiada, o una disposición natural reforzada por fuertes valores personales o éticos. Algunas veces la RC está establecida legalmente, y algunas veces es promulgada legalmente como un valor institucional y deviene en una política gerencial. A menudo la rendición de cuentas permanece meramente como una exhortación.

Donde hay una insuficiente disposición natural a rendir cuentas, a asumir responsabilidad, o a responder, se necesita una presión externa. Puede tomar la forma de una norma legal, que es específica; o puede ser una presión social, generalizada y ambigua. Algunas veces la presión toma la forma de un premio o de un castigo. Hay una creencia generalizada de que tal régimen es sano y apropiado y mucha gente reacciona humanamente ante el. Sin embargo, tiene limitaciones. (Analdo, 1998, p. 55).

\section{¿Quiénes piden cuentas y quienes deben dar cuentas?}

Sobre quienes piden cuentas, el politólogo argentino Guillermo $O$ Donnell señala que la RC a que están sometidas las autoridades y funcionarios públicos se puede dividir en dos categorías: la RC vertical y la RC horizontal, en donde la primera hace referencia a la ejercida por el pueblo, como soberano; mientras que la segunda es aquella ejercida por distintos órganos públicos, como el Parlamento, las EFS, los Tribunales de Justicia, entre otros (O Donnell, 1998). 
Tanto la $R C$ vertical como la $\mathrm{RC}$ horizontal tienen la característica común que cada una visualiza a una distinta categoría de sujeto: una social y la otra institucional, cada una de las cuales tiene un importante rol dentro de la rendición de cuentas, a la vez que permite distinguir los diferentes medios que unos y otros tienen para exigir cuentas.

Cuando se habla de RC vertical se enfoca desde el punto de vista del ciudadano. Esta RC vertical tradicionalmente ha operado en forma periódica aunque discontinua, mediante el mecanismo de las elecciones, cuando los ciudadanos deciden sobre volver a elegir o no al mismo gobernante o partido gobernante que estaba en el poder.

Los expertos señalan que debe avanzarse hacia mecanismos más constantes de RC vertical, ya sean electorales como el referéndum, el plebiscito o la revocatoria de mandato; como también efectivizando los mecanismos que hagan posible el ejercicio de derechos fundamentales como: el derecho de petición y pronta respuesta de las solicitudes de los ciudadanos ante los órganos públicos; el derecho de acceso a la información pública en forma oportuna y transparente, el derecho de denuncia y de atención pronta y cumplida de la misma por parte de las autoridades competentes y el derecho a que se le rindan cuentas o explicaciones en forma justificada.

Por su parte, la RC horizontal comprende la ejercida por órganos públicos según el ámbito de sus competencias, y se subdivide a su vez en inter-orgánica e intra-orgánica.

La primera comprende aquella ejercida por cada órgano público en forma separada y conforme al ámbito de sus atribuciones (Parlamento, las EFS, los Tribunales de Justicia, Defensor de los Habitantes, auditoría interna, entre otros); mientras que la segunda es la RC ejercida por cada órgano público, sea o no de control, a lo interno del personal ,dentro de su propio seno en forma descendente: del jerarca unipersonal o colegia- do al gerente(s), del gerente(s) a los mandos medios y de éstos hacia sus colaboradores.

Sin embargo, de acuerdo con el enfoque sistémico, debe advertirse que la $R C$ vertical y la $R C$ horizontal no deben ser entendidos como procesos enteramente separados uno del otro, sino que ambos interactúan, se complementan y no deben desconocerse mutuamente, puesto que generan sus propias sinergias.

Pero más allá de eso, puede decirse que la RC en una democracia es una responsabilidad de los que la conformamos. Por ello, la RC no solo atañe a quienes ejercen la autoridad para gestionar los asuntos públicos y de los órganos de control propios de la institucionalidad pública que tienen la autoridad para someterla a los distintos tipos de control, sino de que es un deber de todos los funcionarios públicos en general y de la ciudadanía en particular, cada uno de acuerdo a la índole de sus atribuciones y deberes, así como según el distinto grado o nivel de responsabilidad conferida.

\section{¿Qué tipos de controles hay y quienes los ejercen en una democracia?}

El Centro Latinoamericano para el Desarrollo (CLAD, 2000) realiza una distinción entre los controles clásicos y los controles novedosos.

Los controles clásicos se dividen en: control parlamentario ejercido por el Congreso, y en el control de procedimientos, ejercido por las EFS, los tribunales de justicia, las auditorías internas y las auditorías externas, enfocados al control de la legalidad de los procedimientos, sean o no financiero-contables.

Los controles no clásicos o novedosos son de dos tipos: el control por resultados y el control por competencia administrada.

- El control por resultados tiene dos exigencias o presupuestos básicos para poder ser 
ejercido: primero, la existencia de una buena planificación, vinculada al presupuesto, con metas, indicadores y estándares que permitan medir objetivamente los resultados de la gestión; segundo, una buena y accesible información, buena en términos de suficiencia, pertinencia, calidad, actualización, completes y veracidad; accesible en el sentido de que toda persona puede efectivamente solicitar y recibirlas, o bien, sencillamente poder accesarla mediante las herramientas de las nuevas tecnologías de la información y la comunicación (NTIC): Internet, correo electrónico, entre otros.

A partir de esos dos presupuestos es posible contar con las condiciones fácticas para una buena gestión y control interno, en la que se ejecuten y apliquen los fondos públicos en forma adecuada en la satisfacción de las necesidades colectivas y el bien común, permitiéndose de una manera racional la posterior evaluación, el control externo - de la EFS, los tribunales de justicia, el del Parlamento, entre otros- y la responsabilización de los gestores públicos que corresponda.

- El control por competencia administrada surge de los nuevos modelos de gestión pública, que buscan romper con el paradigma de que solo el Estado puede ser prestador de servicios públicos o ejecutor de obras públicas, introduciendo esquemas en los que los particulares puedan participar, aunque siempre bajo la regulación e inspección del Estado como garante de la consecución del interés público.

La filosofía del control por competencia administrada reside en crear modelos de mercado o cuasimercado, en donde existan varios prestadores de servicios, públicos y privados, que compitan por la asignación de fondos públicos y que permitan a los ciudadanos elegir al prestador de los mismos.

Para ello, las autoridades públicas suelen exigir a los prestadores el cumplimiento de ciertas metas de desempeño, las cuales se plasman en compromisos o contratos de gestión bajo ciertas metas y estándares suscritos, derivando en un contrato que suscribe el órgano gubernamental central o autoridad pública reguladora con varios prestadores de servicios públicos que interactúan en un ambiente de competencia o cuasicompetencia, con base en los cuales los burócratas pueden penalizar, recompensar o corregir la acción de los proveedores de estos servicios, buscando aumentar la eficiencia, calidad, entre otros.

Un ejemplo paradigmático del uso de este mecanismo de competencia administrada es Chile, en donde el servicio educativo costeado por el Estado es prestado por centros municipalizados o bien por centros privados, de modo que el padre de familia escoge donde prefiere enviar a sus hijos y el Estado paga directamente ese dinero al centro público o privado que corresponda.

Como síntesis, el CLAD (1998b, p. 38) presenta el siguiente cuadro:

TABLA 2

FORMAS DE CONTROL Y OPERADORES DEL CONTROL

\begin{tabular}{|c|c|c|c|c|c|}
\hline $\begin{array}{l}\text { FORMAS DE } \\
\text { CONTROL Y } \\
\text { OPERADORES }\end{array}$ & $\begin{array}{l}\text { CONTROL } \\
\text { PARIAMENTARIO }\end{array}$ & $\begin{array}{l}\text { CONTROL DE } \\
\text { PROCEIMIENTOS }\end{array}$ & CONTROL & CONTROL DE & $\begin{array}{l}\text { COMPETENCIA } \\
\text { ADMINISTRATIVA }\end{array}$ \\
\hline DEL CONTROL & & & & & \\
\hline Políticos & $x$ & & & 2 & \\
\hline Burócratas & & $x$ & & 1 & 2 \\
\hline Sociedad & & & $x$ & 2 & 2 \\
\hline Competencia & & & & & 1 \\
\hline
\end{tabular}

FueNTE: Tomado de CLAD, 1998, p. 38. 
Los números 1 y 2 incluidos en el control de resultados y en la competencia administrativa, aluden a que ambas al contrario de las otras tres, poseen más de un agente o mecanismo controlador. En este sentido, la numeración sirve para clasificar la importancia de cada uno de los controladores: el 1 equivale al agente principal y el 2 al secundario.

Vemos entonces que hay muchas formas de control y controladores en el sistema democrático, de modo que las EFS si bien tienen un rol central en la RC, lo ejercen dentro de sus respectivas competencias y sin desconocer los roles de los otros actores, a fin de que en definitiva se generen sinergias y apoyos mutuos.

\section{¿Sobre qué aspectos y cómo se rinde cuentas?}

Este es quizás uno de los temas que más interrogantes y controversia genera, ya que tradicionalmente la RC se ha enfocado como una tarea que lleva adelante el gobernante y el funcionario público, usualmente sin seguir un protocolo o modelo determinado estandarizado y mínimo en cuanto a su estructura, contenidos, los parámetros de comparación y evaluación, la calidad de la información, los momentos o el nivel de detalle con que debe cumplirse este deber.

Para efectos de una RC el gobernante o funcionario público realiza diferentes acciones como conferencias de prensa, discursos en actividades públicas, informes, secciones en una página web, todo conducente a satisfacer ese propósito.

Si de informes de RC se trata, los mismos pueden abordar combinaciones sobre distintos aspectos vinculados a la RC: informes financieros, datos estadísticos, referencias al cumplimiento de las leyes y reglamentos, y toda una gama de acciones que muestran logros obtenidos durante un determinado período de gestión aunque por lo general eluden referirse al cumplimiento de las metas concretas trazadas y optan por no explicar las razones de los incumplimientos.

Por lo antes expuesto, Analdo (1998) señala que:

En el vocabulario de la gerencia, la rendición de cuentas al pueblo amenaza con volverse una de esas palabras molestas que puede tomar el significado que quien la menciona o escribe quiera mencionar sin comprometerse. No obstante cuando es expresada con cuidado y precisión, es un concepto invaluable para orientar a las organizaciones y los individuos directamente a las metas y objetivo establecidos.

La rendición de cuentas incluye la misión establecida, la asignación de responsabilidades, los indicadores de resultados, el informe y la evaluación. Promueve el uso disciplinado del manejo por resultados y otras herramientas ejecutivas. Tiene impacto desde el nivel más alto de una organización hasta lo más bajo del rango gerencial... marca una diferencia entre lo esencial y lo no esencial. Rendir cuentas significa ser responsable y sensible a los actos y resultados que se relacionan con la misión de la organización. Para obtener resultados hay que entender claramente la misión o los objetivos de la organización (p. 51).

La obligación de rendir cuentas tiene los siguientes requerimientos (CGR, 1998):

- Es necesario para RC contar con una estructura que garantice la buena marcha de las operaciones y el logro de los objetivos, así como la obtención de información veraz y confiable.

- Establecimiento de un sistema que defina los métodos y formas de hacerlo, cuya información reúna las características de razonabilidad e integridad que debe poseer un in- 
forme de rendición de cuentas de la gestión pública

- Demostrar que se han empleado los recursos con la debida consideración a la economía, eficiencia y eficacia, logro de resultados y valor agregado, de forma que se justifiquen los actos o acciones realizados, sin que quede duda de que fueron correctos y apropiados.

- Que los actos o acciones de los funcionarios públicos sean efectuados según el ordenamiento jurídico y juicio prudente, bajo la exclusiva responsabilidad de quien los ejecute, lo que debe ser debidamente documentado y sujeto a una revisión en forma independiente, profesional y apolítica, así también al informe público de sus resultados y en los casos en que se demuestre que se han cometido deliberadamente errores, tomar oportunamente las acciones correctivas que se ameriten (p. 19).

Asimismo, la Administración Pública Canadiense (1995) ha definido doce atributos de información necesarios para formarse un juicio balanceado y una RC sobre la eficacia de la organización, los cuales se detallan a continuación:

\section{- Orientación Gerencial}

El grado hasta el cual los alcances de una organización, los programas que la componen, y sus empleados, están claros, bien integrados y comprendidos y propiamente reflejados en los planes y estructura de la organización, delegaciones de autoridad y en los procesos de toma de decisiones.

\section{- Relevancia}

El alcance hasta el cual el programa continúa teniendo sentido, respecto a los problemas o condiciones hasta los cuales se propone que responda.
- Uso Adecuado

El alcance hasta el cual el diseño de un programa o sus componentes principales, y el nivel de esfuerzo realizado son lógicos, considerando los objetivos específicos que deben lograrse (modo de conseguir los objetivos).

- Logro de Resultados Esperados

El alcance hasta el cual los objetivos y metas han sido logrados acorde a lo presupuestado.

- Aceptación

El alcance hasta el cual los clientes para quienes se diseñó el programa lo consideran satisfactorio (expectativas del público).

- Impactos Secundarios

El alcance hasta el cual otras consecuencias importantes han ocurrido, ya sea intencionadas o no, positivas o negativas.

- Costos y Productividad

La relación entre los costos, entradas y producciones.

- Reacción a los Cambios

La habilidad de una organización para adaptarse a los cambios en aspectos tales como mercado, tecnología, entre otros.

- Resultados Financieros

La unión de, y la rendición de cuentas para, costos e ingresos y la rendición de cuentas y la valuación de activos para pasivos y equidad (estados financieros).

- Ambiente Laboral

El alcance hasta el cual la organización proporciona una atmósfera de trabajo y oportunidades apropiadas a sus empleados, para 
desarrollos y logros, y fomenta compromisos, iniciativas y seguridad.

\section{- Protección de Activos}

El alcance hasta el cual los activos importantes -tales como fuente de suministro, propiedades de valor, personal clave, acuerdos, registros e información importantesson salvaguardos con el propósito de que la organización esté protegida del peligro de pérdidas que podrían amenazar el éxito, credibilidad, continuidad y tal vez su propia existencia.

\section{- Monitoreo y Reportes}

El alcance hasta el cual los aspectos claves pertinentes al desempeño y esfuerzo organizacional son identificados, reportados y cuidadosamente monitoreados o controlados.

\section{¿Qué persigue la RC? ¿Cuál es su norte en el contexto de nuestros países?}

En los últimos veinte años, la RC en los países de la región latinoamericana se enmarca dentro de un contexto de crisis conceptual, financiera y de gestión del modelo de Estado benefactor e interventor, así como crisis del modelo productivo basado en la sustitución de importaciones y en el abastecimiento del mercado interno, a lo cual se ha sumado una crisis del sistema burocrático weberiano y del mismo sistema democrático de representación política, por lo que la RC está indisolublementre asociada al buen gobierno y a la gobernabilidad, o mejor, a la republicanización de nuestros países.

Históricamente, el detonante de este estado de cosas en la región fue la crisis de la deuda externa a inicios de los años ochenta del siglo XX, obligando a programas de ajuste estructural que llevaron al repliegue y/o disminución en sus prestaciones o servicios a la ciudadanía y a una drástica reducción del peso interventor del Estado en la economía, vacío que fue llenado por el mercado como nuevo actor protagónico que determina muchas de las orientaciones de las políticas públicas en todos los campos.

Pero esas crisis internas se producen además dentro de un nuevo contexto internacional marcado por la globalización económica, la liberación o apertura comercial y una creciente competitividad, lo cual obliga a drásticos cambios paradigmáticos en el modelo productivo, que pasa a enfocarse al mercado externo y a reemprender el camino del crecimiento económico.

A lo interno de cada país, la crisis del modelo de Estado ha obligado a la necesidad de su replanteamiento, tanto en torno a su papel en la economía, como respecto al tradicional rol que había venido jugando como prestador directo de servicios públicos, ya que se propugna por un mayor apertura a que grupos empresariales privados y organizaciones de la sociedad civil sean los que presten los servicios públicos, con lo cual se produce un cambio sustancial en el papel del Estado, puesto que se propugna porque en muchos casos pase de ser prestador directo de servicios públicos a transformarse en regulador y controlador de la gestión que realizan los particulares con los bienes o servicios públicos concesionados o dados bajo otros títulos jurídicos para su administración, a fin de garantizar que pese a su gestión privada operen siempre bajo principios y parámetros adecuados al interés público.

Asimismo, en lo que respecta a la burocracia, los países de la región han transitado por distintos estadios, ya que no siempre se han podido librar del nefasto sistema de botín político, compadrazgo y favoritismo, pero en otros muchos esa tarea sí fue acometida, instaurando sistemas meritocráticos o de servicio civil, que garantizan un acceso a la función pública por méritos e idoneidad y en condiciones de igualdad, una estabili- 
dad que los libre de la arbitrariedad de los políticos de turno, un profesionalismo o competencia técnica para las complejas y extensas tareas públicas y un apego a los principios de jerarquía y de legalidad.

Sin embargo, lo cierto es que aparecieron algunas disfuncionalidades no previstas de la burocracia, ya que aunque fue creada para el servicio de los intereses de la colectividad, en el devenir histórico adquirió conciencia como clase que tiene sus propios intereses, lo cual la alejó de la gente y la tornó en tecnocrática, autoreferenciada, enfocada en el cumplimiento del formalismo de los procedimientos y rutinas administrativas, además de excesivamente jerarquizada, centralizada y rígidamente sometida a esquemas aislados de especialidad funcional, provocando pérdida o carencia de una adecuada direccionalidad.

Lo anterior se produce dentro de un nuevo modelo económico y las exigencias de la competitividad internacional que demandan flexibilidad, adaptación a cambios constantes y muy rápidos, innovación y orientación al cliente, exigencias totalmente contrarias al comportamiento burocrático tradicional.

Pero a la vez, en lo que atañe al sistema político, la democracia representativa también entra en crisis, debido a la insuficiencia de una democracia meramente delegativa.

Esto se produce sobretodo cuando los partidos políticos dejan de ser cuerpos sociales intermedios que hacen la función articular y canalizar la participación ciudadana en la cosa pública y no responden a los intereses de la ciudadanía, sino a los intereses de fuertes grupos de interés organizados, partidos políticos que pueden terminar respondiendo solo a esos intereses sectores sin mirar suficientemente al bien común, a lo que se suma la crisis económica, la crisis del modelo de Estado y la crisis de la burocracia antes señalada, generando un creciente descontento y desencanto de la ciudadanía con la democracia, por la inoperancia del sistema como un todo para darle al pueblo una adecuada calidad de vida.

Como se observa, la maquinaria estatal que tradicionalmente se ha movido gracias a dos actores como lo son los partidos políticos y la burocracia entra en crisis, a raíz de las disfuncionalidades ya mencionadas, lo cual sumado a la crisis del modelo económico y a la crisis financiera ha provocado enormes perjuicios al eficiente accionar estatal.

Tal y como ha sido advertido por varios especialistas, esa ineficiencia se ha querido subsanar introduciendo las nuevas técnicas del management (buen gobierno corporativo, planificación estratégica, enfoque sistémico de las organizaciones, el rediseño de procesos de trabajo, valoración y gestión de riesgos, liderazgo, cuadro de mando integral, áreas de mejoramiento o mejoramiento continuo, orientación al cliente y a la calidad, sistema de control interno, indicadores de gestión, y gestión por resultados), asociados a nuevos enfoques en materia financiera-presupuestaria (vinculación plan-presupuesto-evaluación), recursos humanos (flexibilización laboral, organizaciones que aprenden, gestión por competencias, ética y valores, empoderamiento, polifuncionalidad, remuneración ligada a la contribución o logro de resultados, calidad y servicio al cliente, insourcing, outsourcing, comportamiento organizacional -motivación, cultura y clima organizacional-).

Todo lo anterior, potenciado mediante el uso más intenso de las nuevas tecnologías de la información y la comunicación (sistemas de información como registros y bases de datos electrónicos) así como lo relativo al gobierno digital.

El "management" es una denominación que por sí misma enfatiza y se usa para hacer referencia a la introducción de técnicas exitosas del sector privado en el sector público, lo cual puede y debe hacerse pero no "bis a bis", como lo han señalado enfáticamente autores como Crozier ( $p$. 
6), debida adaptación, en virtud de los distintos contextos, fines, intereses, así como naturaleza de los fondos, potestades y regímenes jurídicos que están en juego.

Por lo tanto, la RC se ha venido enfocando como un medio o instrumento útil por su asociación con el buen gobierno. El concepto de buen gobierno consiste en aquel que trata de la "buena gobernanza" o acción de gobernar, acción que supone la promoción y respecto de los derechos humanos, así como las exigencias de un actuar gubernamental ético, eficiente, eficaz, económico, equitativo y ecológicamente comprometido, so pena de responsabilización, por aquellas conductas $u$ omisiones que se aparten injustificadamente de esos imperativos de la gestión pública.

Eso significa que la RC no es un fin en sí mismo sino que está destinada a cumplir un propósito instrumental como lo es alcanzar el buen gobierno, y con ello una mejor calidad de vida y suma de felicidad de los habitantes.

Si bien el norte de la RC se ha diseccionado hacia el buen gobierno -enfoque que es trascendental para el caso de la nueva ola de democracias de la región latinoamericana que surgió en los años noventa del siglo XX había iniciada con una ola anterior en varios países europeos como Portugal y España en la década de los años setenta del siglo XX-, la RC tiene un propósito que se sitúa más allá del buen gobierno, y es lo que algunos autores denominan gobernabilidad y otros como Oszlak (1999) Ilaman republicanización de nuestros países.

Según Prats (1998) la gobernabilidad "...es un atributo de la sociedad no de sus gobiernos y se refiere a la capacidad de una determinada sociedad para enfrentar positivamente los desafíos y oportunidades que se plantean en un tiempo determinado. Gobernabilidad no es pues estabilidad política, sino creación de condiciones para reconocer y enfrentar colectivamente los retos y oportunidades de cada tiempo" (p. 17).

Como bien explican Rivera y Bejarano (2002):

...en síntesis la gobernabilidad es la integración del acto de gobernar con las respuestas que da la sociedad a ese acto, gobernar con el aporte real del Gobierno y de los habitantes... siendo lo determinante la relación gobierno-sociedad, la distancia y la frecuencia con que se solicitan, brindan y reciben los servicios del Gobierno, haciendo que el papel de receptor varíe entre consumidor, usuario, cliente o ciudadano. De esta forma, la sociedad, un elemento presente pero hasta ese momento muy lejano ....cobra verdadera importancia y se suma a la ecuación de servicio público... y la forma en que sociedad y gobierno interactúan fundamenta el nivel de gobernabilidad, (...) nivel que depende de dos factores: la calidad del sistema institucional existente, y las capacidades de gobernación de los actores sociales (los gobernantes y la sociedad civil: sus valores, actitudes y modelos mentales) para trabajar y apoyarse solidariamente en procurar de alcanzar el bienestar social (p. 34).

De acuerdo con Adam Przeworski (2003), el desafío actual de la gobernabilidad democrática consiste en encontrar "...un espacio virtuoso entre el incremento de los poderes del Estado y el incremento del control sobre el Estado, para permitir al gobierno que gobierne y a los gobernados que controlen al gobierno"

$Y$ es que, muchos autores insisten en que el cambio de paradigma del modelo del Estado benefactor, interventor y empresario, asociada a la crisis y disfuncionalidades del modelo burocrático, han conducido a revitalizar la $\mathrm{RC}$ no como una actividad aislada ni un fin en sí mismo, sino que ha de ser comprendida mediante un enfoque sistémico, que permita enmarcarla 
dentro de todo un conjunto aunado de cambios, medios y direccionalidad de los esfuerzos, en la que está en juego no solo la eficiencia, eficacia y economía del accionar del Estado, sino la propia gobernabilidad y credibilidad en la efectividad del sistema democrático e institucional para dar calidad de vida a la ciudadanía.

Dos son entonces los nortes de la RC: primero, hacer más eficiente el aparato estatal y con ello el logro de un "buen gobierno", y segundo, la republicanización de nuestros país al servir, al decir de Oszlac como "...un medio de relegitimación social y política del mismo" (1999, p. 6), ya que lo que está en juego en el fondo es la propia gobernabilidad y credibilidad en la efectividad del sistema democrático e institucional para dar calidad de vida a la ciudadanía y satisfacer sus derechos.

\section{¿Qué consecuencias de no rendir una efectiva $R C$ ?}

Al inicio de este ensayo planteamos nuestra propia definición de la RC entendida como"la obligación de toda persona a la que le es conferida una responsabilidad de dar cuenta del encargo recibido, haciendo un descargo que puede ser satisfactorio o insatisfactorio, debiendo provocar en el primer caso reconocimiento o efectos favorables, y en el segundo caso desaprobación o consecuencias negativas".

En ese sentido, hay quienes estiman que el sistema de RC debe contener estímulos apropiados para quienes hagan un efectivo y satisfactorio ejercicio de $\mathrm{RC}$, mientras que con respecto a un ejercicio inapropiado o deficiente de la RC, las opiniones se dividen entre quienes abogan por insistir en la RC como un mejoramiento de la gestión, es decir, en la aplicación de meras mejoras correctivas, pero por otro lado hay quienes a ello añaden un sistema de responsabilización múltiple en los órdenes penales, administrativos, pecuniarios, político y social.

Quienes defienden solo los métodos correctivos estiman que ello favorece condiciones más adecuadas para que los informes sean más confiables, dado que los gerentes saben que el sistema únicamente podrá reclamarles la introducción de mejoras en ciertas áreas del desempeño, sin necesidad de ninguna consecuencia sancionatoria ulterior; pero hay también quienes por el contrario defienden a la par de ello, el que existan medidas de castigo de diversa índole claramente establecidas en el ordenamiento jurídico, estimando que ello contribuye a presionar por mejores resultados.

No obstante lo anterior, la opinión hoy en día en boga se sintetiza en que:

La existencia de mecanismos que permiten la responsabilización de los funcionarios públicos por los resultados de su gestión, está relacionada con la existencia de una cultura que los induzca y haga posibles. Las condiciones sistémicas que generan un ámbito propicio a la rendición de cuentas, incluyen, entre otros factores, la transparencia en la gestión pública, la publicidad de los actos gubernamentales, la existencia de un marco normativo que establezca los mecanismos de responsabilización que abarquen a todos los niveles de la pirámide institucional del Estado, y la independencia de las instituciones encargadas de determinar responsabilidades (1998, p. 78).

Por lo tanto, los ordenamientos jurídicos de cada país son los que han de recoger en sus disposiciones los aspectos antes indicados, y por ello, éstos pueden variar en la amplitud e intensidad en su desarrollo de país en país. 


\section{El sistema de RC y sus componentes ¿Qué es un sistema? Bases conceptuales generales}

Hoy en día se suele hablar mucho de sistemas: sistema político, sistema jurídico, sistema de salud, sistema educativo, entre otros muchos; lo cual responde a una visión en la cual se superan el método cartesiano, que está muy arraigado en nuestra mentalidad y nos suele impedir una visión holística, integral o de conjunto, conocido modernamente como el enfoque sistémico.

Fue en la década de los años veinte del siglo XX que Ludwing Von Bertalanffy (2009) propuso el concepto de "sistema", cuyo mérito es incorporar al análisis la consideración de las interrelaciones existentes entre las partes, como un todo armónico e inseparable.

La palabra "sistema" proviene de las ciencias biológicas y físicas, pasando luego a todas las ramas del saber, y busca complementar el enfoque reduccionista utilizado por el hombre para desarrollar el conocimiento científico que tiende a una subdivisión mayor del todo y al estudio particular de esas subdivisiones.

La Teoría General de Sistemas estudia las totalidades, definidas como sistemas compuestos de partes o subsistemas interrelacionados entre sí, que constantemente interactúan con su medio ambiente, en donde cada una de sus partes está conjuntada a través de una ordenación lógica, que vincula sus actos a un fin común u objetivos del sistema.

Más que una metodología, la teoría de sistemas consiste en una actitud o disposición mental para examinar los fenómenos y ver la realidad, en donde no interesan los partes en forma aislada o independiente sino también sus interrelaciones y sinergias.

Según la Teoría General de Sistemas la realidad es un todo complejo con un comportamiento determinado y carácter único, por eso la estudia a partir de una visión integral y por ende, no fragmentada, simplista o reduccionista.

El enfoque de sistemas es un método de análisis que puede ser aplicado a cualquier situación en la que se identifique una estructura sistémica, compuesta por subsistemas y microsistemas, que cuenten con cuatro elementos: los insumos (imputs- entrada al sistema), los procesos de conversión, los resultados (outputs-salida del sistema) y la retroalimentación.

Los sistemas necesitan alimentarse de elementos -imputs- provenientes del medio en el cual operan. Así, las instituciones requieren recursos o medios humanos, materiales, financieros, tecnológicos, jurídicos, documentales, entre otros; lo cual constituyen los insumos o combustible (energía) del sistema, que lo mueve y lo hace operar.

El proceso de conversión es la razón de ser del sistema, en el sentido de que en el mismo se desarrollan sus funciones para cumplir sus objetivos, transformando -mediante procesos legislativos, judiciales, administrativos, electorales, fiscalizadores, entre otros- la energía recibida en productos o servicios, los cuales que vuelven al medio o son utilizados a su vez como insumos o energía para otra fase del proceso de conversión.

La salida del sistema es el producto o servicio final que el sistema pone en el medio, que pueden ser positivos o favorables para la comunidad o negativos para ella. El balance de lo favorable o desfavorable de dicho producto o servicio determinará su aceptación o no en el medio, el cual creará las reacciones tendientes a su aceptación, pero también a su eliminación o modificación cuando proceda.

La retroalimentación se refiere a que por diversas razones los objetivos no suelen alcanzarse en forma exacta y completa, lo cual crea la necesidad de un mecanismo de control que le informe al sistema como se está logrando el objetivo y 
las desviaciones de lo alcanzado con respecto a éste, lo cual se logra a través de lo que se conoce como gestión de riesgos y una batería de indicadores apropiados.

La información que provee ese mecanismo o subsistema de control es conocido como "retroalimentación" y es utilizado por el sistema para orientar sus actividades cuando el objetivo no se está realizando y ese mecanismo le ayuda a asegurar sus fines. Puede decirse que modernamente la retroalimentación no es sino el control interno, la evaluación de resultados y el control externo que también suele existir y que opera como un doble candado.

La ciencia de la Administración ha adoptado el enfoque sistémico, ya que tiene muchos elementos básicos que interactuán: planificación, presupuestación, organización o dirección, ejecución, control y evaluación.

Hay que hacer notar que tradicionalmente las organizaciones se definieron como sistemas cerrados, es decir, como totalidades desligadas del entorno, desconociendo su necesidad de tomar insumos ambientales para su trabajo, y quedándose en aspectos de su funcionamiento interno -autoreferenciados o endogámicos-, incapaces de ajustarse al sistema de su entorno, ya que se miran a sí mismas como metas del sistema de un organismo cerrado -lo que podríamos Ilamar la enfermedad del autismo organizacional-.

Eso le puede ocurrir a un EFS, la cual refugiada en su independencia, competencia e imparcialidad puede llegar a verse como un sistema cerrado, inmune al entorno y sus demandas, al estar meramente especializada en su lenguaje y procesos, pero incapaz de entenderse a sí misma dentro de un sistema mayor, porque se puede caer en el error de considerar que no existe más que una única forma de producir un resultado esperado y además se olvidan del ciudadano como soberano y de la retroalimentación que el entorno les puede dar para mejorar su fiscalización.

Entonces, hablar de sistema significa considerar que existen varios elementos que intervienen en diferentes procesos, los cuales están estrechamente interrelacionados, guardando un orden e interdependencia adecuado a efecto de lograr un objetivo común.

\section{Los sistemas de una organización}

Actualmente la dirección organizacional debe aplicar técnicas científicas que le permitan ser eficiente y eficaz, ante el alto nivel de complejidad de las relaciones entre la organización y el marco ambiental en que se desenvuelve, que conlleve a la conducción de la institución por los cauces del progreso y la modernización.

Desde la perspectiva de una institución como un sistema abierto se han establecido tres grupos de sistemas:

- Sistemas de recursos

- Sistemas operativos

- Sistema Decisional

El sistema de recursos hace referencia a los insumos que le dan energía a la organización para que opere que son: a) el subsistema de recursos humanos, b) el subsistema de recursos financieros, c) el subsistema tecnológico y d) el subsistema logístico.

El sistema operativo es el que transforma los insumos haciendo uso del sistema de recursos con el cual interactúa, proceso que llevará a emitir productos o servicios finales. En el sistema operativo confluye una gran actividad directiva en todas sus formas, ya que comprende la definición de objetivos, la decisión de qué y cómo se va a producir, aspectos que se deben reflejar en la estructura asumida por la organización. 
Está compuesto por varios subsistemas producción, ventas, entre otros; es decir, para una entidad pública como una EFS, son sus procesos sustantivos de fiscalización, en sus variadas modalidades: control previo, control posterior, control de legalidad, control financiero, control de resultados y la responsabilización.

El sistema decisional es el sistema encargado del gobierno integral de la institución, que comprende toda la red de decisiones en todos los niveles. El ejercicio del poder de decisión debe hacerse sobre una base razonable de valoración de riesgos y áreas críticas, más nunca con base en pura intuición o percepción, para lo cual utiliza tres subsistemas administrativos: a) el Subsistema de Planificación-Presupuesto, b) el Subsistema de Información y c) el Subsistema de Control Interno. Al sistema decisional y tres subsistemas administrativos se les llama sistema de gobierno o sistema de gestión.

El sistema decisional o de gestión comprende a toda la organización y para ello, las instituciones se constituyen por niveles de autoridad, con un tipo de gestión y control asignado, sin importar el área de actividad ocupacional (dirección financiera, dirección de auditoria, dirección de informática, entre otros).

Tanto institucionalmente como en cada nivel o rama de actividad, la gestión se realiza a través de tres elementos básicos: la determinación de objetivos, su ejecución y su control.

Los tres subsistemas fundamentales del sistema decisional están relacionados entre sí: el subsistema de planificación-presupuesto y el subsistema de control de la gestión son los reguladores de la actividad, en tanto que el Subsistema de Información constituye la red de comunicación ente ambos subsistemas.

Uno no puede existir sin el otro: el subsistema planificación-presupuesto representa el co- mienzo del subsistema de control de la gestión - de lo contrario no se sabría qué se va a controlar-, mientras que el subsistema de información realiza la importante labor de comunicación y retroalimentación que hace posible que la administración conozca si su gestión está alcanzado los objetivos y las causas por las cuales no se estén logrando, para así reorientar las acciones mediante decisiones oportunas.

De hecho no se puede ejercer control si antes no se ha planificado la acción, igualmente si a los encargados en la administración de ejercerlo no les llega información de qué y cómo se ha ejecutado lo planeado.

Por su importancia, vamos a detenernos en cada uno de esos tres subsistemas del sistema decisional.

\section{El sistema decisional de la organización y sus subsistemas}

\section{EL SUBSISTEMA DE PLANIFICACIÓN-PRESUPUESTO}

Este subsistema es concebido como un binomio inseparable, en el tanto se constituye como un instrumento para la utilización racional de los escasos recursos de la sociedad y para la efectiva asignación y destino de los mismos en procura del bienestar de la población.

Al definir un plan y un presupuesto coherente con el mismo a partir de una visión interdependiente de ambos, se logra transformar decisiones en acciones que llevarán a actividades conducentes a realizar los resultados esperados.

Para que este sistema funcione con eficacia es prácticamente imprescindible que se cumpla con todos los componentes de planes operativos a corto plazo (un año), de planes tácticos a mediado plazo (hasta cinco años), ambos fundados en un plan estratégico de largo plazo (más de cinco años), puesto que una planificación de 
corto plazo será circunstancial e insuficiente si no se enmarca dentro de un plan de desarrollo de más largo aliento, sobretodo tratándose de planes y programas que por su naturaleza suelen exceder de un año para su implantación, mantenimiento y frutos. Asimismo, los planes de mediano plazo no podrán ser cumplidos si no se cuenta con los planes anuales operativos para su realización, que contengan objetivos, metas e indicadores precisos, medibles, viables, apropiados, entre otros.

Estos planes han de estar asociados y nunca separados del plan financiero presupuestario vinculado usualmente a cuatro etapas: a) formulación, b) discusión, aprobación y promulgación, c) ejecución y contabilidad y d) control y evaluación.

\section{PROCESO PRESUPUESTARIO}

ETAPA DEL PROCESO

\section{ACTORES INVOLUCRADO EN LA ETAPA}

Formulación del anteproyecto de presupuesto por parte de las distintas dependencias gubernamentales e integración del proyecto de presupuesto.

Formulación Generalmente queda a cargo de la secretaría/ministerio de Finanzas (Economía, Hacienda), aunque todas las agencias públicas participan en la formulación, incluyendo a las que dependen del legislativo y judicial.

Análisis, discusión y aprobación

Esta etapa da inicio cuando el Poder Ejecutivo somete al Legislativo el proyecto de presupuesto. El Congreso y sus diversas comisiones analiza, discute y posteriormente aprueba el presupuesto. En cada país hay diversas modalidades y el papel del Legislativo frente al Ejecutivo y sus capacidades de modificación, aprobación y rechazo, así como ocasionalmente superar un veto presidencial son diferentes en cada país.

El inicio del año fiscal marca el comienzo del ejercicio del presupuesto aprobado. Todas las agencias públicas aplican entonces los recursos del presupuesto en sus diversas actividades.

Ejercicio Generalmente existen acciones y planes públicos que fueron formulados a través de complejos sistemas normativos y burocráticos. El ejercicio del gasto constituye una etapa clave para el análisis presupuestal, el acceso a la información sobre el gasto público y los sistemas de transparencia y rendición de cuentas.

Las acciones de control, evaluación y auditoria, que ocurren tanto al momento del ejercicio del gasto, por medio de mecanismo de control interno del gobierno, como durante y al finalizar el periodo o año fiscal, a través del control externo. Es importante conocer si dentro

Control y evaluación de cada país existe un sistema nacional de control y auditoria, así como si se siguen distintas normas y procedimientos que aseguren la legalidad y responsabilidad de los funcionarios públicos al aplicar el gasto, y al desempeñar sus varias funciones; asimismo es importante evaluar el grado de cumplimiento de los objetivos y metas establecidos en los distintos programas y acciones gubernamentales.

Fuente: Tomado de FUNDAR, Índice Latinoamericano de Transparencia Presupuestaria, 2005. 
Al presupuesto modernamente no se le presta atención como medio utilizado por el Gobierno para adquirir insumos (equipo, materiales, recursos humanos), sino que por el contrario se le concibe como medio para el cumplimiento de sus funciones y la obtención de resultados de calidad.

Como sistema tiene entradas (inptus), proceso y salidas (outputs).

Las entradas al sistema son los elementos de planificación (nacional, sectorial, regional e institucional, según corresponda), los elementos concretos del marco jurídico de la institución de que se trate, las políticas, los objetivos generales estratégicos definidos por el nivel superior y la retroalimentación de los resultados de ejercicios anteriores.

El proceso, el cual esta conformado por las cuatro etapas ya vista supra, las cuales tienen una ocurrencia secuencial y coadyuvan, como subsistemas dentro de un sistema general, a la materialización de un resultado final.

Las salidas del sistema, los cuales se refieren a los resultados físicos (medidos mediante indicadores y metas alcanzadas comparadas respecto a las previamente planeadas) y los resultados financieros (lo presupuestado versus lo efectivamente ejecutado; el balance financiero patrimonial y el costeo de los servicios y bienes producidos), es decir, esas salidas serán bienes y servicios producidos para la satisfacción de las necesidades de la colectividad, e informes o estados financieros propiamente dichos.

Es necesario indicar que el sistema descansa sobre una infraestructura jurídica (normas reguladoras) y en una infraestructura administrativa (contabilidad, tesorería, presupuesto, proveeduría, servicios generales -conserjería, seguridad, transportes, recursos humanos, entre otros) y una infraestructura técnico-instrumental (metodologías para formular el plan-presupuesto, las normas contables, los clasificadores presupuestarios estandarizados e incluso los denominados "compromisos o contratos de gestión" que tienen la función de que el plano directivo concerte con el gerente general la consecución de ciertas metas y/o mejoras, para que éste a su vez haga lo propio con los jefes a su cargo, y los jefes lo hagan con sus subalternos -evaluación del desempeño de los funcionarios públicos todos no por percepción sino por resultados obtenidos-.

\section{EL SUBSISTEMA DE INFORMACIÓN}

Son un elemento fundamental para la toma de decisiones y sin embargo, su carencia o débil calidad y ordenamiento es uno de los elementos que suelen afectar nuestras organizaciones, lo cual impide que se puedan tomar decisiones racionales y sean más de índole intuitiva, cuando no improvisadas.

El subsistema de información es el soporte del sistema de gestión, pues suministra los datos necesarios a la Administración para que ésta conozca el grado de alcance de los objetivos, y si es del caso, reorientar las actividades, por lo que debe concebirse en forma integral.

Este subsistema tiene a su vez varios componentes:

1. Información normativa (leyes, reglamentos y reglas en general que rigen el quehacer institucional).

2. Información de planificación y presupuesto (sobre objetivos, metas, indicadores, estándares).

3. Información del entorno (pone en contacto a la organización con los actores externos: políticos, económicos, ciudadanos, entre otros). 
4. Información operativa (recoge los detalles de las operaciones o trabajos que se hacen en la organización como producto del trabajo cotidiano), en cuatro áreas: a) financiera-contable; b) productos o servicios realizados; c) aspectos de recursos humanos; y d) divulgación o mercadeo de los bienes y servicios producidos para la población.

5. Información de control y gestión (compara entre sí la información obtenida por los subsistemas de información operativa, normativa y de planificación-presupuesto, para conocer hasta en qué grado se cumple).

6. Administración: es tomar la información producida y conservarla en un archivo (de cada oficina o general), debidamente clasificada y utilizando tarjetas, índices, entre otros, que permitan organizarla para facilitar su posterior y ágil búsqueda.

7. Sistemas de información internos (son base de datos informáticas que permiten ingresar la información producida, ordenarla, obtener reportes, estadísticas, entre otros).

\section{EL SUBSISTEMA DE CONTROL}

En la teoría de sistema aplicada a la organización, el control opera como un regulador y retroalimentador de la actividad institucional.

Su aplicación y ejercicio supone la preexistencia de un sistema de control interno que la Administración tiene la responsabilidad primaria de diseñar, establecer, mantener y perfeccionar, lo cual hace conforme a parámetros internacionales como las normas COSO (Committee of Sponsoring Organizations of the Treadway Commission) y sus más recientes actualizaciones así como a las normas vigentes en cada país, las cuales suelen hablar de cinco componentes básicos del control interno: ambiente de control; información y comunicación, control, supervisión y evaluación de riesgo.

Asimismo, con base en ese control debe asegurarse que se pueden comparar los resultados de la actividad con los objetivos, metas e indicadores propuestos. Ese es un control eminentemente gerencial, cuya responsabilidad en su implantación, mantenimiento y perfeccionamiento corresponde a los respectivos jerarcas y jefes, puesto que permite que los responsables tomen decisiones oportunas y apropiadas.

Finalmente, se dice que estos tres subsistemas: el de planificación-presupuesto; el de información y el de control deben conformar un proceso administrativo integralmente concebido, que se suele denominar: Sistema de Control Integrado de Gestión.

Señala Analdo, (1998):

La rendición de cuentas prosperará bajo una filosofía de gestión conveniente, un enfoque apropiado de control, y controles bien elegidos.

Uno debe distinguir entre control, que es el ejercicio del poder o autoridad, y controles, que son los mecanismos o instrumentos elegidos para llevar a cabo el control. El control comienza con el deseo de ejercer la autoridad, de gestionar, de administrar, de intervenir:

Estar en control significa:

- Saber dónde quiere ir uno en relación con los recursos disponibles.

- Estar bien organizado para lograrlo.

- Ser tan eficiente como lo sea posible.

- Entender qué resultados deben alcanzarse.

- Reconocer los resultados reales alcanzados.

- Demostrar lo que se ha logrado. 
Estar en control implica tener expectativas de desempeño acordes a: los objetivos del programa y objetivos operativos, así como estándares de servicio. Es más, significa ser capaz de demostrar que se está en control (p. 80).

\section{Los componentes del sistema de $R C$}

El sistema de RC está inserto dentro de un macro sistema más amplio que es el sistema democrático.

El sistema de $\mathrm{RC}$ debe irse institucionalizando a fin de que opere como un todo, en forma integrada e interrelacionada.

Para tal efecto, un factor muy importante de esa institucionalización ha sido las leyes de administración financiera integrada que se han promulgado en los últimos años en nuestros países, en donde el binomio plan-presupuesto aparece como la columna vertebral del sistema de rendición de cuentas, puesto que dicho binomio está claramente asociado al logro de resultados físicos y financieros conforme a criterios de eficiencia, eficacia y economía, superándose la visión de mera percepción de ingresos y aplicación de gastos, propios de una contabilidad presupuestaria.

Estas leyes de administración financiera han enfatizado también en la implantación de una contabilidad patrimonial y no meramente presupuestaria en toda la Administración Pública, que permite contar con estados financieros certificados e incluso auditados, así como una contabilidad que adempás sea analítica, que permita tener costeado cada uno de los productos (bienes y servicios proporcionados por la Administración Pública) para así poder ver si vale la pena pagar ese costo, si es razonable, excesivo y tomar medidas correctivas.

Un segundo factor primordial es el relacionado con los sistema de información, aspecto en don- de las nuevas normas de control interno hacen un énfasis especial, como uno de sus cinco componentes básicos.

Se dice que la información es la "liquidez de la rendición de cuentas", puesto que es como la sangre que debe correr y fluir por todo el cuerpo institucional, con la mayor transparencia, veracidad, exactitud, confiabilidad y completes posible. Muy importante es señalar que información debe estar accesible a la ciudadanía y puesta a su disposición en la web de la respectiva entidad pública, para facilitar el escrutinio de la sociedad civil que costea con el pago de los tributos al Estado.

Estos dos factores -el jurídico y el informativohan de verse en forma articulada, para evitar lecturas asistemáticas del conjunto de normas dispersas y usualmente inconexas que rigen la $R C$.

Se suele señalar que el sistema de RC tiene seis componentes básicos:

1. Normativo

2. Orgánico

3. Funcional

4. Instrumental

5. Socio-Ciudadano

6. Personal-cultural

El componente normativo es aquel conjunto de reglas, principios y valores que regulan el funcionamiento y operación del sistema de RC, incluido lo referente a la responzabilización. Estas reglas pueden ser implícitos o explícitos, y estar derivadas de la Constitución, la ley, los reglamentos o incluso determinados instrumentos de índole contractual.

El componente orgánico es aquel conjunto de instituciones y órganos públicos a los que la Constitución y la ley asignan concretas respon- 
sabilidades de administración, rectoría, control y responsabilización en materia de $\mathrm{RC}$.

En cuanto a rectoría, nos referimos a la autoridad para establecer políticas y normas en determinadas áreas: Ministerio de Planificación en materia de planes a corto, mediano y largo plazo, con alcances nacionales, regionales, sectoriales e institucionales; Ministerio de Hacienda en materia de presupuesto, contabilidad, administraci'no de bienes muebles e inmuebles, endeudamiento público y tesorería, y las EFS como rectoras del sistema de control y fiscalización superior, entidades que algunos señalan deben avanzar hacia realizar una meta- evaluación (evaluación de la evaluación) insertando su competente criterio y sugerencias sobre la gestión pública y incluso sobre el manejo macroeconómico del país.

El componente funcional se refiere a las competencias, funciones o medios técnicos y jurídicos que cada órgano tiene asignados: la Administración como rendidora de cuentas y los órganos públicos de control dentro de su propia esfera de competencias (autoridades de planificación y hacendarias; autoridades de representación política como Parlamentos y corporaciones municipales; autoridades de control como EFS, Auditorias Internas, Defensorías, Tribunales; entre otros).

El componente instrumental se refiere a las herramientas de planificación, presupuestación, establecimiento de indicadores de gestión, de estándares de desempeño y de medios de seguimiento, sistemas de información, control y evaluación de resultados necesarios para una efectiva gestión, RC y responsabilización. Incluye los requisitos de forma y fondo relativos a los informes de rendimiento o desempeño que los gestores públicos deben periódicamente rendir, así como el régimen operativo de "incentivos y castigos" que del mismo se derivan para hacerlo exigible y efectivo.
El componente socio-ciudadano se refiere al rol participativo cada vez más conciente, activo y responsable de la ciudadanía, tanto en forma individual como asociadas, a través de una multiplicidad de organizaciones sociales (cámaras empresariales, sindicatos, cooperativas, asociaciones de desarrollo, grupos campesinos, grupos indígenas, grupos eclesiales, grupos profesionales, etc.). Incluye distinta formas de demanda de servicios, información, participación, de denuncia, etc. Finalmente, un elemento de singular importancia dentro de este componente son los Medios de Comunicación Social -incluidas las Nuevas Tecnologías de la Información y la Comunicación-, con el innegable peso mediático que los mismos poseen en nuestras sociedades y como forjadores de la opinión pública.

El componente personal-cultural se refiere a las actitudes, comportamientos, formas de pensar, etc. que pernean esta materia y a la necesidad de trabajar con planes a mediano y largo plazo para favorecer esta cultura, tanto en los gestores públicos como en la misma ciudadanía.

Finalmente, y como marco general debemos señalar que todo SRC (Sistema de rendición de cuentas) ha de tener las siguientes características:

1. Transparencia, que implica que se debe proporcionar la información en forma clara, confiable, eficiente y oportuna sobre el diseño, la gestión y los resultados de la política pública y que se le dé amplia difusión.

2. Integridad, que se relaciona con un desempeño adecuado y honorable en la gestión de los fondos públicos.

3. Imparcialidad, que implica el trato igual y decente a los ciudadanos, conforme con el principio de igualdad desarrollado en el artículo 33 de la constitución Política y la ju- 
risprudencia constitucional de los tribunales costarricenses.

4. Confiabilidad, que garantiza el respeto de los derechos de los ciudadanos y el cumplimiento de la ley.

5. Autonomía, que se refiere a la independencia de la función técnica del poder político.

6. Continuidad, que busca el desarrollo de sistemas permanentes de planificación, monitoreo y evaluación de la gestión de fondos públicos.

\section{Las EFS, RC y sistema democrático}

En el sistema democrático de derecho, se supera el gobierno basado en el capricho de los gobernantes por el sometimiento de los mismos a la Ley y el Derecho, en el tanto sus posibles desviaciones son sometidas a un control de legalidad, el cual es aplicado por excelencia aunque no exclusivamente por dos órganos públicos, que son: un órgano de justicia administrativa, generalmente residenciado en el poder judicial, y un ente de fiscalización superior (EFS) que ejerce tanto un control de legalidad como un control financiero-contable, llamado Tribunal o Corte de Cuentas, o bien, Contraloría o Auditoría General de la República.

La existencia de EFS, así como el ejercicio independiente, profesionalmente competente y objetivo de sus funciones, ha sido una de las más importantes y difíciles conquistas de un sistema democrático, que vino a reemplazar la ajeneidad al control propia de los regímenes monárquicos predemocráticos o de los regímenes autoritarios en general, y generalmente ejercen su labor con una menor o mayor grado de vinculación con el Parlamento.
En la región de América Latina y el Caribe el diseño orgánico-funcional de las EFS ha recibido dos grandes influencias: una europea- continental y otra anglosajona, cada una de las cuales ha desarrollado su propio modelo con algunas variaciones, pero lo cierto es que ambos modelos han impactado el desarrollo de los modelos de las EFS en nuestra región.

El modelo europeo-continental se caracteriza por un diseño colegiado de la EFS, en cabeza de Tribunales o Cortes de Cuentas, que ejercen funciones auditoras de control de legalidad y de control sobre el manejo financiero-contable del Estado y las demás instituciones o empresas públicas, las cuales típicamente se realizan a través de auditorias de naturaleza financiero-contable, así como de auditorias de cumplimiento o legalidad.

La particularidad del modelo europeo-continental de EFS, es que en la mayoría de casos tienen atribuidas además funciones de orden jurisdiccional- Ilamado también control fiscal o de responsabilidad contable-, que opera fuera de la órbita del poder judicial y por lo mismo como jurisdicción fuera de su control.

Por su parte, el modelo anglo-sajón se caracteriza por un diseño unipersonal de la EFS, en cabeza de Contralorías y Auditorías Generales o Nacionales, que ejercen también funciones auditoras de control de legalidad y de control sobre el manejo financiero-contable del Estado y las demás instituciones públicas.

La particularidad del modelo anglosajón de EFS es que este tipo de órganos tienen atribuidas además funciones o competencias que las facultan para realizar un control sobre la gestión - llamado también control de eficiencia-.

Para ello, la Oficina de Contabilidad General de los EEUU (GAO), acuñó el término "auditoría de 
desempeño", su homóloga de Gran Bretaña la llama "auditoría de la optimización de recursos", mientras que la Auditoria General de Canadá la denomina "auditoría comprensiva", las cuales pueden variar en algunos enfoques o planteamientos metodológicos pero todas buscan verificar si la gestión ha conducido al logro de resultados.

En nuestra región, la recepción de ambos modelos ha dado lugar a múltiples combinaciones de esos dos modelos básicos en cuanto al diseño orgánico, tenemos órganos colegiados tipo Tribunales o Cortes de Cuentas en El Salvador, República Dominicana, Honduras y Brasil, así como Auditoría Nacional de la Nación en Argentina; en tanto que en otros países lo que existe son Contralorías o Auditorias Generales de tipo unipersonal, como sucede en México, Panamá, Colombia, Venezuela, Costa Rica, Ecuador y otros.

En lo relativo a las atribuciones de control en el orden jurisdiccional fiscal, si bien desde la época de la independencia se produjo en la mayoría de nuestros países, una recepción del modelo continental-europeo, básicamente el español, lo cierto es que con el devenir histórico ha perdido importancia -cuando no es que desapareció jurídicamente- e incluso donde aún permanece es fuertemente criticado por su histórica y lamentable inoperancia.

$Y$ es que, si bien universalmente se reconocen los aportes de la auditoria financiera contable y de la auditoria de legalidad para controlar una correcta y adecuada gestión pública, también desde hace muchos años se viene insistiendo en la insuficiencia de dichos tipos de auditoria para mejorar el desempeño de las entidades auditadas, en el tanto la eficiencia no se consigue solo controlando los aspectos financieros y de cumplimiento de las normas.

\section{El control por resultados}

Por ello, no es extraño que hoy en día el denominador común de todas las EFS de la región es que sus atribuciones se han ampliado más allá del control de legalidad y el control del manejo financiero-contable, para abarcar también el control de eficiencia, salvo en el caso de la EFS de Chile, que termina aplicándolo por la vía de los exámenes y recomendaciones que permiten los nuevos enfoques mundiales del control interno (COSO y COSO RM).

Esto explica que a nivel de las EFS de la OLACEFS (Organización Latinoamericana y del Caribe de Entidades Fiscalizadoras Superiores), se practiquen no solo auditorias financiero-contables y auditorias de cumplimiento o legalidad, sino que también se haya incursionado en el desarrollo de "auditorias de gestión", que buscan ejercer un control sobre la eficacia, la eficiencia y la economía de la gestión.

Para tal efecto, es necesario partir de parámetros, criterios o indicadores de eficiencia, eficacia y economía, los cuales constituyen nociones que no resultan fáciles de captar y por ello ofrecemos a continuación un cuadro guía sobre el eje básico sobre el cual gira cada una:

$$
\text { TABLA } 4
$$

TIPOS DE INDICADORES

\begin{tabular}{ll}
\hline $\begin{array}{c}\text { TIPO DE } \\
\text { INDICADOR }\end{array}$ & \multicolumn{1}{c}{ EJE CONCEPTUAL } \\
QUE LO DEFINE
\end{tabular}

FUENTE: Elaboración propia 
Los expertos apuntan que no debe desconocerse la importancia del logro de objetivos y metas (eficacia), pero ello no puede evaluarse independientemente del costo, de la productividad y de la calidad.

La elaboración de criterios o indicadores de eficiencia, eficacia y economía de gestión requiere que éstos estén informados de ciertos atributos o características tales como pertinencia, relevancia, confiabilidad e impacto, de modo que reflejen con la mayor propiedad posible información útil y apropiada sobre el real desempeño que una unidad, departamento, ministerio o institución ha tenido en un período dado, en términos de logro de objetivos y metas, costos asociados a los productos o servicios ofrecidos, productividad y calidad.

En este aspecto, es necesario resaltar que en los países de la región en los últimos quince años se han venido impulsando reformas legales y administrativas tendientes a modernizar la administración financiera del Estado y demás entidades públicas, mediante la introducción de un enfoque integrado o comprensivo de sus distintos componentes: contabilidad, presupuesto, tesorería, administración de bienes y endeudamiento o crédito público.

De esta forma se han aprobado nuevas leyes de Administración Financiera, que han venido ordenando y articulando los componentes ya mencionados, a fin de asegurar un funcionamiento uniforme, armónico y mutuamente complementario de cada uno de ellos.

Estas leyes de administración financiera tienen la común característica de que han adoptado los criterios de eficacia, eficiencia y economía como parte importante de los procesos de planificación, presupuestación, liquidación y evaluación, reconociendo su importancia para mejorar los resultados de la gestión pública.
Los jerarcas suelen ser obligados por esas leyes financieras a rendir informes de evaluación de resultados y liquidación de la ejecución presupuestaria financiera y física conforme a ese tipo de criterios, los cuales suelen ir mejorando año con año, conforme se internaliza una cultura de evaluación de resultados.

En el mismo sentido, las normas de control interno también exigen que se disponga de un sistema que prevenga contra el despilfarro, el mal uso o abuso, la falta de cumplimiento de normas legales, la carencia de eficiencia, eficacia y economía en las operaciones, etc., reforzándose sin duda la gestión por resultados y la RC.

\section{La RC en el quehacer de las EFS a nivel mundial, regional, zonal y nacional Plano MUNDIAL}

Las EFS desde el año 1953 crearon la International Organization of Supreme Audit Institutions -en adelante INTOSAI- que es una organización internacional a nivel mundial que las agrupa.

La INTOSAI en el último Congreso trienal celebrado en Hungría en el mes octubre de 2004 (XVIII), aprobó el primer plan estratégico (20052010) de la organización, cuya visión así como la primera de sus cuatro metas estratégicas disponen:

\section{VISIÓN}

Promover el buen gobierno, habilitando a las EFS para que ayuden a sus respectivas administraciones a mejorar la gestión, perfeccionar la transparencia, garantizar la obligación de rendir cuentas, mantener la credibilidad, luchar contra la corrupción, promover la confianza pública y fomentar el uso de los recursos públicos en beneficio de los pueblos. 


\section{METAS ESTRATÉGICAS}

Meta 1.- Rendición de cuentas y normas profesionales

Promover EFS sólidas, independientes y multidisciplinarias alentando a las EFS a liderar mediante el ejemplo y contribuyendo al desarrollo y adopción de normas profesionales apropiadas y eficaces.

Como se observa, la RC aparece explícitamente referenciada en la visión organizacional, como instrumento conducente a promover un buen gobierno, y dentro del que la EFS tienen la obligación de garantizar que dichas cuentas sean cabalmente rendidas.

Obsérvese que la meta primera vincula las normas profesionales con la RC, lo cual es muy revelador de la importancia y el valor que se les concede a la mismas en relación con la $\mathrm{RC}$, puesto que esas normas profesionales son los criterios o parámetros que debe seguirse en cada materia: control interno, auditoría de cumplimiento o legalidad, normas contables, auditoría financiera, auditoría de gestión así como las normas de garantizan la independencia, imparcialidad y objetividad del fiscalizador, entre las que destacan las Normas Éticas de auditoria.

Y es que el propio Banco Mundial desde el año 2004 ha aprobado una estrategia interna que reconoce el papel de la EFS en la promoción del buen gobierno y en la administración financiera de sus administraciones nacionales, por lo que dicha estrategia del Banco busca garantizar que las EFS reciban el apoyo idóneo para cumplir sus misiones, tal y como en efecto ha ocurrido.

\section{Plano regional}

La más antigua organización regional que reúne a las EFS es la OLACEFS, creada en la década de los sesentas, y que hoy forma parte de un total de siete grupos regionales que abarcan todo el mundo CARISAI, AFROSAI, ARABOSAI, ASOSAI, SPASAI.

Por su parte, la OLACEFS como entidad regional cuenta también con plan estratégico 2006-2010, en el cual se ha definido como objetivo general "convertirse en un socio estratégico de las EFS miembros, fortaleciendo su capacidad para promover el buen gobierno, la transparencia, la rendición de cuentas y luchar contra la corrupción, dentro del ámbito de sus respectivas competencias" (OLACEFS, 2006, p. 4 ), de donde se extrae con claridad que la rendición de cuentas es uno de los ejes de la gestión de la organización en los próximos años.

Asimismo, conforme a ese objetivo general, un objetivo específico de dicha gestión es "Promover en las EFS el desarrollo de actividades en materia de transparencia, rendición de cuentas y lucha contra el fraude y la corrupción".

Es de resaltar que la XIV Asamblea General de la OLACEFS celebrada en noviembre de 2004 en Buenos Aires consideró como uno de sus tres temas técnicos uno dedicado a la Rendición de Cuentas, cuya ponencia principal la preparó la EFS de Panamá, llegándose a las siguientes conclusiones y recomendaciones:

- Existe un amplio consenso sobre la necesidad de encontrar una definición unificada novedosa de la rendición de cuentas y de sus diferentes aspectos en los países miembros.

- Las EFS acordaron considerar la definición del Banco Mundial, según la cual la rendición de cuentas significa que los servidores civiles no solo tienen la obligación de informar sobre sus actividades y transacciones, sino también de justificarlas. 
- La rendición de cuentas también debería incluir un análisis de la gestión.

Como fruto de esa Asamblea, se creó la Comisión Técnica de Rendición de Cuentas, presidida por la Contraloría General de Costa Rica y con el concurso de representantes de las EFS de Panamá, Chile, Argentina y Honduras.

Dicha Comisión tiene elaborado un plan de trabajo estratégico que pasamos a transcribir, en lo que se estima son sus aspectos centrales:

\section{Misión de la comisión de rendición de cuentas}

Promover en la OLACEFS y sus EFS miembros, mediante funciones de estudio e investigaciones permanentes, el desarrollo de métodos de fiscalización para los procesos de rendición de cuentas, cuyos resultados deberán expresarse en propuestas normativas y metodológicas que colaboren al óptimo ejercicio de la función fiscalizadora superior.

\section{Objetivos de la Comisión}

Generales:

- Desarrollar y proveer a las EFS de las herramientas normativas y metodológicas necesarias para fiscalizar el proceso de Rendición de Cuentas de la administración.

- Desarrollar herramientas para el fortalecimiento de la participación ciudadana en el análisis de la información generada en el proceso de rendición de cuentas.

Factores clave de éxito

1. Apoyo a las EFS miembros en la facilitación de la información requerida.
2. Claridad sobre el concepto de rendición de cuentas que va a operacionalizar la OLACEFS.

\section{PROCESO DE INVESTIGACIÓN Y DESARROLLO}

A) Objetivo

Desarrollar en la OLACEFS, por medio de la Comisión, el grado de conocimiento necesario para poder facilitar a nivel de país la implantación y funcionamiento de un sistema de rendición de cuentas como elemento básico para un buen gobierno y que pueda ser compartido con las demás Entidades de Fiscalización Superior de América Latina y Caribe.

b) Propósito

Coadyuvar con la Administración Pública y las demás organizaciones de la sociedad Latinoamericana y el Caribe en el desarrollo de herramientas que le permitan informarle al ciudadano qué hicieron los gobernantes y funcionarios públicos en general con el mandato y los recursos que se pusieron bajo su administración para el cumplimiento de los fines encomendados y así fortalecer la gobernabilidad en cada país.

Resultados de corto plazo:

- Claridad sobre el estado de los sistemas de rendición de cuentas a nivel de los países miembros.

- Diseño de un proceso de investigación permanente en temas relacionados con la rendición de cuentas y la gobernabilidad.

- Diseño de un proceso para el desarrollo de herramientas adecuadas para la rendición de cuentas, con identificación de los principales informes a generar. 
- Acuerdos con instituciones públicas clave en cada país con las cuales trabajar en el desarrollo de esta temática".

Como fruto del trabajo de dicha Comisión la OLACCEFS aprobó a finales del año 2009 lo que se conoce como la Declaración de Asunción, la cual contiene un conjunto de ocho principios sobre la rendición de cuentas, que orientan el quehacer de las EFS en esta materia.

\section{Nivel zonal y nacional}

A nivel de los países centroamericanos, República Dominicana y Cuba se cuenta con una organización zonal de las EFS denominada Organización Centroamericana y del Caribe de Entidades de Fiscalización Superior en adelante OCCEFS, la cual ha venido trabajando en el tema de la RC desde hace varios años.

Para tal propósito, el Banco Mundial financió un primer préstamo con el cual fue posible que la OCCEFS tuviera su propia página WEB, así como cada país utilizó esos fondos para contratar consultorías que tendientes a mejorar algunas áreas que estimaron de mayor interés nacional en esta materia.

Dichos informes por país y general para la región datan del año 2003, y por su calidad, cobertura y amplitud constituyen unos insumos excelentes para comprender la situación general de cada nación, sus procesos histórico-institucionales y retos.

Además, es importante señalar que el Banco Mundial ha realizado una nueva donación a la OCCEFS, para desarrollar un proyecto denominado "Fortalecimiento de los sistemas institucionales de Rendición de Cuentas a través de las Instituciones Superiores de Auditoria de Centro América y República Dominicana", el cual está muy orientado hacia las finanzas públicas, un conjunto de indicadores y la creación de un índice de rendición de cuentas. para los países centroamericanos, Panamá y República Dominicana.

\section{Las EFS ¿garantes o promotoras de la RC?}

La INTOSAI afirma en su Misión que las EFS son garantes de la RC, mientras que otros sostienen que ellas son básicamente promotoras de que la $\mathrm{RC}$ se pueda ir produciendo en forma cada vez más efectiva en nuestros países. Pero independientemente del enfoque, se coincide en la idea de que las EFS tienen que ejercer un liderazgo y un rol clave en esta materia para estar vigilante de su adecuado funcionamiento.

Y es que, durante la IV Jornada EUROSAI - OLACEFS, 16 de noviembre de 2005 Tema "Bases Metodología generales destinadas a medir y evaluar el impacto de la acción fiscalizadora superior en el ahorro y en el buen uso de los recursos públicos", la contribución de la CGR Chile había señalado:

El Banco Mundial ha definido la Rendición de Cuentas a partir de dos componentes fundamentales, cuales son, la obligación que asiste a políticos y funcionarios quienes administran los recursos públicos -considerados en su sentido mas amplio, de informar y justificar sus actos ante quienes les han delegado dicha capacidad, esto es, la ciudadanía, y la capacidad de sancionarlos cuando ellos violen o incumplan sus obligaciones (enforcement).

Podemos afirmar que existe Rendición de Cuentas propiamente tal en la medida que existan ambos elementos. A su vez, la información que los agentes públicos deben proporcionar a la ciudadanía en relación con la administración de los recursos de propiedad 
común precisa de una instancia validadora, capaz de emitir una opinión independiente relativa a la calidad, pertinencia y transparencia de la rendición cursada.

Las diferentes legislaciones nacionales existentes en la Región atribuyen esta revisión de la Rendición de Cuentas Gubernamental al ámbito de competencia de las Entidades Fiscalizadoras Superiores, cualquiera sea su capacidad de control.

No obstante, no es menos cierto que, en la medida que Órgano Superior de Control esté dotado de facultades más amplias y cuente con una mayor independencia, la cobertura, profundidad y objetividad del examen que pueda ejercer respecto de la Rendición de Cuentas también mejorará(p. 3).

Por ello, algunos expertos señalan que así como la auditoria financiera practicada por las EFS ha sido útil para generar credibilidad en los estados financieros que presenta la Administración, los informes de auditoria de gestión que preparan y emiten las EFS tiene el propósito de buscar generar confiabilidad en la RC contenida en los informes de evaluación y de rendimiento que los gestores públicos presentan sobre los resultados esperados y los resultados alcanzados.

En este sentido, el rol de las EFS en la RC dependerá de los concretos mandatos normativos, estrategias y metodologías que éstas asuman, así como de las capacidades institucionales, personales y materiales propias de la realidad de cada una de ellas, a fin de incursionar en este nuevo pero muy importante campo que permite a dar información vital a la sociedad sobre el quehacer de los gobernantes y de la Administración Pública.

Importantes retos se han venido presentando a lo largo de los años a las EFS para ir introduciendo nuevas destrezas, habilidades, metodo- logías y enfoques a su tradición concepción de auditoría, a fin de ir construyendo y haciendo experiencia en la realización de distintos servicios de auditoria de gestión, con el concurso de profesionales en las distintas ramas del saber, instruidos en las metodologías de la autoría de gestión.

Esta tarea resulta más difícil cuando las leyes no les otorgan a las EFS un mandato claro, o aún haciéndolo, puede suceder que el peso inercial del enfoque tradicional y la falta de expertisse en el enfoque novedoso dificultan su accionar en esa dirección.

Además, este tipo de labor se puede ver muy afectada por la misma inoperancia y dificultades de los gestores públicos en establecer un adecuado sistema organizativo con todos sus componentes debidamente desarrollos (subsistema de recursos, subsistema operativo y subsistema decisional o gerencial), agravado por sistemas de información generalmente poco desarrollados o impertinentes para dar información de calidad, unos indicadores de gestión inexistentes o los diseñados no poseen los atributos de calidad requeridos, aunado a una pobre cultura y preparación en evaluación y rendición de cuentas por parte de los propios gestores públicos.

En esas circunstancias, las EFS deben saber direccionar sus esfuerzos de control con un horizonte claro, pero también con un sentido procesual, de mejora continua, de persistencia y constancia, a fin de ir paulatinamente generando las condiciones apropiadas para que los entes auditados caminen en esta dirección.

Asimismo, se enfatiza en la necesidad de que las propias EFS a lo interno de las mismas avancen en esta materia, desde sus procesos de planificación estratégica, sus sistemas de evaluación de riesgo e indicadores de gestión, desde la calidad de sus mismos informes y su adecuada divulgación, de modo que sean ejemplo ante 
la Administración y la ciudadanía de entidades modernas y ajustadas ellas mismas a la RC.

Finalmente, no cabe duda de la importancia de los informes periódicos que suelen rendir las EFS a los Congresos, a fin de que éstos realmente contengan información completa, actualizada y útil para una adecuada valoración por parte del Congreso de la Rendición de Cuentas que hace el Ejecutivo y el sector descentralizado en general, haciendo una labor de control político mucho más fundada.

\section{COMENTARIO FINAL}

Es pacíficamente aceptado que la calidad es determinada por el cliente, por lo que el buen gobierno y la buena RC es determinada por el pueblo, con lo cual la democracia participativa y aún la democracia representativa irán sin duda adquiriendo nuevas y más cualificadas dimensiones conforme la construcción del sistema de rendición de cuentas avance en su perfeccionamiento.

De esa manera, se enfatiza en el carácter instrumental de la triada de nociones - $R C$, buen gobierno y gobernabilidad- así como de sus mecanismos aplicativos, los cuales lejos de constituir un fin en sí mismos o incluso un capricho o entelequia intelectual, son los verdaderos nuevos motores que van a impulsar a nuestras sociedades hacia la buena gestión pública, el perfeccionamiento de todas y cada una de sus instituciones -sin excepción-, el protagonismo ciudadano en la cosa pública, la calidad de vida -buen viviro mayor suma de felicidad de la nación y a una mayor credibilidad del sistema democrático de gobierno en los albores del tercer milenio.

\section{REFERENCIAS}

Analdo M. (1998) Rendición de Cuentas, Informe de Rendimiento, Auditoría Comprensiva - Una perspectiva integrada. Canadá: CCAF-FCVI.

Centro Latinoamericano de Administración para el Desarrollo (1998). Una Nueva Gestión Pública para la América Latina. Caracas, Venezuela.

Centro Latinoamericano de Administración para el Desarrollo (2000) La Responsabilización en la Nueva Gestión Pública Latinoamericana. Caracas, Venezuela.

Contraloría General de Chile (16 de noviembre de 2005). Bases Metodología generales destinadas a medir y evaluar el impacto de la acción fiscalizadora superior en el ahorro y en el buen uso de los recursos públicos. Ponencia ante la IV Jornada EUROSAI - OLACEFS.

Contraloría General de la República de Costa Rica (1998). Seminario Taller La Rendición de Cuentas y sus sistemas fundamentales. San José, Costa Rica.

Contraloría General de la República de Costa Rica (2003). Rendición de Cuentas y Evaluación de Resultados, retos actuales de la fiscalización. Monitoreo del Entorno Institucional 2003.

Contraloría General de la República. (1998) Seminario Taller "La Rendición de Cuentas y sus sistemas fundamentales". San José, Costa Rica.

Comisión la OLACCEFS (2009). Declaración de Asunción. Recuperada el 11-noviembre- 2009, de: http://cgrw01.cgr.go.cr/pls/portal/docs/PAGE/ CTRC/ARCHIVOS/TAB2326766/DECLARACI\%D3 N\%20DE\%20ASUNCI\%D3N.DOC.

Crozier, M. (1999). El fenónemo Burocrático. Madrid, Editorial Magallanes.

Declaración de los derechos del hombre y del ciudadano. Recuperado el 10 de noviembre de http:// es.wikisource.org/wiki/Declaraci\%C3\%B3n_de_ los_Derechos_del_Hombre_y_del_Ciudadano 
Espinoza, D.\& Von Bertalanffy, L. (2009) Teoría general de sistemas. Editorial Ariel.

Estado de la Nación (2005). Índice Latinoamericano de Transparencia Presupuestaria. San José.

O Donell, G. (1998). Acountability horizontal e novas poliarquías. Revista Lua Nova, 44, pp. Inserte el numero de paginas del artículo.

Oszlak, O. (1999) El Estado irresponsable: conceptos foráneos y conductas autóctonas. Buenos Aires: Mimeo.

Peruzzotti, E. \& Smulovitz, C. (2002) Held to Account: Experiences of Social Accountability in Latin America. Journal of Human Development, 3 (2).

Prats Catalá, J. (1998) Servicio Civil y Gobernabilidad. Revista Iberoamericana de Administración Pública. (1), julio-diciembre. pp. 8.

Rivera, R. \& Bejarano R. (2002) Gestión Pública: gobernabilidad y capacitación: una experiencia del Servicio Civil costarricense. Revista de Servicio Civil, (13), pp. 14.

Przeworski, A. (2003) Democracia y Mercado, Editorial Akalac.

RECIBIDO: 19-10-2009

ACEPTADO: 25-11-2009 